\title{
Mental Health Challenges Related to Neoliberal Capitalism in the United States
}

\author{
Anna Zeira ${ }^{1}$ (D) \\ Received: 12 February 2021 / Accepted: 14 May 2021 / Published online: 25 May 2021 \\ (c) The Author(s), under exclusive licence to Springer Science+Business Media, LLC, part of Springer Nature 2021
}

\begin{abstract}
Rates of mental illness have increased dramatically over the past 15 years in the United States [Products—Data Briefs-Number 283-August 2017. Centers for Disease Control and Prevention. https://www.cdc.gov/nchs/products/databriefs/db283. htm. Published August 15, 2017]. Additionally, life expectancy has fallen over the past several years due to increases in death from suicide, opioid overdose, and alcoholic liver cirrhosis as reported by Case and Deaton [Deaths of despair and the future of capitalism. Princeton University Press, 2020]. Over the last decade some have questioned whether these changes are due to neoliberal capitalist policies and ideologies. Neoliberal capitalism incorporates theories of eliminating all restrictions on the market and decreasing government assistance programs as reported by Harvey [A brief history of neoliberalism, Oxford University Press, 2005]. Since then these policies have led to income inequality, disempowerment of workers, outsourcing of manufacturing jobs, inadequate social services, mass incarceration and an expensive and ineffective healthcare system as reported by Case and Deaton [Deaths of despair and the future of capitalism. Princeton University Press, 2020] and NkansahAmankra et al. [International Journal of Health Services 43(2):217-240, 2013]. Studies have shown that the consequences of these policies and ideologies likely have a role in increasing rates of mental illness. This paper will discuss how these factors increase mental distress and postulate ways that mental health professionals can advocate for change.
\end{abstract}

Keywords Social determinants of mental health · Epidemiology and statistics $\cdot$ Economic policy $\cdot$ Healthcare policy · Neoliberal capitalism $\cdot$ Community mental health

Over the past 15 years, antidepressant use has increased in the United States by nearly 65\% (Products-Data Briefs, 2017). From 2017 to 2018, 19\% of adults in the United States experienced a mental illness-an increase of 1.5 million people when compared to the previous year (State \& of Mental Health in America, 2021). These do not include the increases in distress after COVID-19, which has resulted in heightened rates of moderate to severe depression, anxiety, and suicidal ideation (Shade, 2021). Additionally, life expectancy, which has increased yearly since 1918, has decreased over the past several years in the United States due to dramatic rises in deaths from suicide, alcoholism, and drug overdoses (Case \& Deaton, 2020). Over the past decade, several economists, journalists, sociologists, and mental health practitioners have posited that the increases in mental illness

Anna Zeira

azeira@som.umaryland.edu

1 University of Maryland/Sheppard Pratt Residency Psychiatry Program, 701 W Pratt Street, Baltimore, MD 21201, USA and distress are due to neoliberal economic policies and ideologies. In his book The Selfish Capitalist, psychologist Oliver James found that twice as many people suffer from emotional distress in the English-speaking nations that have adapted neoliberal capitalist policies when compared to people in the Western European nations which did not (James, 2008). He also notes the rapid increase in emotional distress in the United States since the 1980s when the country began to implement neoliberal policies such as eliminating restrictions on the trade market and cutting social services (James, 2008). Economic policies such as deregulation of industry and decreased public sector spending starting in the 1980s have spawned wealth inequality, mass incarceration, and job insecurity, which all can contribute to emotional distress (Case \& Deaton, 2020; Wilkinson \& Pickett, 2011). Additionally, economic and social policies created a change in ideology favoring individualism, materialism, and competitiveness, which are not compatible with human needs such as social connection and community, leading to anxiety and depression (James, 2008). Furthermore, through poor access 
to mental healthcare due to the for profit healthcare system and the medicalization of emotional distress due to the rise of biological psychiatry, how we treat mental illness in the United States has also contributed to rising rates of anxiety and depression (Case \& Deaton, 2020; Cohen, 2017). This article will explain the economic and social tenets of neoliberalism and how they exacerbate emotional distress. Additionally, this article will discuss how neoliberalism has affected the mental healthcare system further contributing to the rise in mental illness. Lastly, there will be a discussion about how we, as mental health providers, can advocate for systemic change.

\section{Neoliberalism}

For the purposes of this discussion, neoliberalism refers to the economic theory that human well-being can be enhanced by individual entrepreneurship and that the government's responsibility is to create an institutional framework that allows for it (Harvey, 2005). Markets are seen as optimal structures and the assumption is that if they were allowed to function without restraint, they would be able to serve all economic needs and generate full employment for all those who wish to work (Harvey, 2005). From this point of view, it is essential to eliminate restrictions on markets by decreasing the strength of unions, privatizing state enterprises, and opening domestic markets to foreign capital and goods (Shaikh, 2014). These policies deviated from the Keynesian economic policy in place after the Second World War that focused on full employment and the welfare of its citizens and used the State's power to intervene in market processes to achieve this (Harvey, 2005). Corporate activities were highly regulated and working class institutions were influential within the state apparatus (Harvey, 2005). By the end of the 1960s the economy was in turmoil while unemployment and inflation soared (Harvey, 2005). Neoliberalism became popular in order to solve this economic crisis (Harvey, 2005). In his book, A Brief History of Neoliberalism, David Harvey argues that the upper class supported these policies in order to further their own power and influence because they felt threatened by the decrease in their share in the national income (Harvey, 2005). Neoliberal policies were broadly enacted through the Reagan administration with corporate tax breaks and incentives, deregulation of business, and the introduction of working practices that strongly favor employers over unions (Harvey, 2005). This was accompanied by transferring resources from public to private ownership and contracting out services that were once provided by the public sector (Moncrieff, 2001). The state also drastically reduced public sector spending and eliminated social programs (Moncrieff, 2001). Trade liberalization and deregulation of foreign financial investment led to increased volume of trade which demanded high rates of consumption and also provided sources of cheap labor abroad putting downward pressure on wages in the US (Moncrieff, 2001). Although Neoliberal policies were billed as attempts to enhance individual freedoms, forms of surveillance and policing became a key strategy to deal with social problems when social services were minimized (Harvey, 2005). This worked to maintain social order as well as uphold private property and corporate interests (Harvey, 2005). Neoliberalization has not been successful at increasing capital accumulation with the exception of the economic elite (Harvey, 2005). These policies have also led to staggering income inequality, disempowerment of workers in their ability to advocate for themselves, outsourcing of manufacturing jobs overseas, inadequate social services, mass incarceration and a healthcare system that is not only expensive but ineffective in providing for its citizens (Case \& Deaton, 2020; Nkansah-Amankra et al., 2013). With these policies came increased inequality as the wages of the top $1 \%$ of earners grew by $160.3 \%$ from 1979-2019 while wages for the working class have either decreased or remained the same (Mishel \& Kandra, 2020). Working conditions have also suffered due to the decreased power of unions which has led to longer hours, increased work intensity, and less worker control of how and where work is performed (Moncrieff, 2001). Through deregulation, the free market became a vehicle for consolidation of power allowing corporations to exercise control over large segments of the economy giving them the power to influence the political process and protect their interests (Harvey, 2005). Neoliberalism is not confined to economics but also represents the evaluative social order in which the merits of human actions are assessed by their market value (Davies, 2017). Constant messages about benefits of the commercialization of more aspects of life and increases in trade helped to make consumerism more popular and spread the message that fulfillment can be obtained from material affluence (Moncrieff, 2001). Competitiveness was also encouraged not just through consumerism, but also as a virtue of individualism (Moncrieff, 2001). There was a shift from an acceptance of collective virtues to individualism and self-reliance (Moncrieff, 2001). Faith in the free market to provide for everyone assumed that the people who were not successful were unsuccessful due to their own faults and not willing to work hard enough to achieve success (Davies, 2017). Ideologically, neoliberal capitalism sees competition as a defining characteristic of human nature, that citizens are able to exercise democratic choices and maximize their quality of life by purchasing, and that the market rewards merit so the rich are seen as 
superior and their success means success for all (Moncrieff, 2001).

\section{Neoliberal Policy and Mental IIIness}

As stated above, neoliberal capitalism has led to an increase in inequality and worsened working conditions. Although cost of living increased, wages have remained stagnant requiring minimum wage workers to work more hours to cover their living expenses (Mishel \& Kandra, 2020). Decreased funding for social programs and welfare reform has also contributed to increased diagnosis of mental illness as traditional welfare programs have shifted to only provide for people with medical or psychiatric illness (Hansen et al., 2014). These outcomes themselves have been shown to cause distress likely contributing to increased rates of mental illness, substance abuse, and suicide.

In recent years there has been an increased focus on social determinants of health and widespread acceptance that there are strong associations between poverty and mental illness (Allen et al., 2014). The World Health Organization's 2014 report Social Determinants of Mental Health showed that common mental disorders such as anxiety and depression are distributed along an economic gradient (Allen et al., 2014). The report suggests that people with lower socioeconomic status are more likely to be exposed to adverse childhood experiences increasing the likelihood of mental illness (Allen et al., 2014). This is one potential explanation for rising rates of mental illness as a consequence of increased poverty or "near poverty" from wage stagnation and fewer welfare programs (Cohen, 2017; NkansahAmankra et al., 2013). However, in their book The Spirit Level, Richard Wilkinson and Kate Pickett show that inequality also seems to have a large impact on mental health for everyone regardless of social class (Wilkinson \& Pickett, 2011). These researchers compared rates of mental illness in countries with higher income inequality such as the United States to countries with lower income inequality such as Japan and found a more than threefold difference in rates of mental illness and a stronger tendency toward drug use in less egalitarian countries (Wilkinson \& Pickett, 2011). They believe that a larger difference in income inequality leads to increased importance of social status heightening status competition and causing increased rates of chronic stress (Wilkinson \& Pickett, 2011).

Other recent developments that can be attributed as phenomena of neoliberal capitalism, such as the loss of meaningful work and worsening job opportunities for workingclass people, may contribute to increasing rates of mental illness (Hari, 2019). People in the US are working longer hours and are increasingly unsatisfied with their jobs (Hari, 2019). In their recent book Deaths of Despair and the
Future of Capitalism, economists Anne Case and Angus Deaton track recent corporate and government practices that effect the working class, which they believe have led to the increased death rates from suicide, drug overdose and alcoholic cirrhosis since 1999. These combined rates were much higher in working-class white people without a college degree (Case \& Deaton, 2020). Workers without secondary education face short-term jobs with high turnover, with many dropping out of the workforce entirely (Case \& Deaton, 2020). With blue-collar labor replaced by cheap foreign alternatives, manufacturing jobs can no longer offer the stability or opportunities for advancement enjoyed by previous generations, (Case \& Deaton, 2020). Furthermore, jobs that are available to those without college degrees are service jobs often outsourced to staffing firms that don't provide workers with adequate benefits, long term contracts, or opportunity for promotion (Case \& Deaton, 2020). Outsourced labor and increasingly popular gig work do not provide workers with the stability, social cohesion, and meaning that were once provided by direct employment by companies and manufacturing jobs (Case \& Deaton, 2020). Through interviewing and tracking health outcomes of British civil servants, psychiatrist Michael Marmot found that lower level civil servants had an increased risk of psychiatric illness largely due to having little control over their work and feeling a lack of balance between efforts and rewards (Stansfeld et al., 1999). With less control of their work and fewer opportunities for recognition and promotion, workers often derive less meaning in work, which causes increased anxiety and depression, and thereby fuels rising deaths and substance abuse among white working class men (Case \& Deaton, 2020; Hari, 2019). It is difficult for the less-educated workforce to escape this situation as intergenerational social mobility has decreased significantly as well (Wilkinson \& Pickett, 2011).

In 1996, President Clinton signed the Personal Responsibility and Work Opportunity Act putting stricter requirements on traditional welfare such as a five-year limit for benefits, stricter eligibility, and work participation requirements (Hansen et al., 2014). Changing these policies did not decrease the need for financial support, so the many of the people who needed assistance applied for Social Security income (SSI) instead (Hansen et al., 2014). This can be seen through the dramatic increases in Social Security recipients since 1996 which reached a 50-100\% growth in the number of young adult beneficiaries by 2000 (Hansen et al., 2014). However, these benefits can only be received with a medical or psychiatric diagnosis, with psychiatric diagnosis being the largest diagnostic category (Hansen et al., 2014). This is also likely a significant driver for the increase in mental illness diagnoses and medication consumption as taking psychiatric medication is frequently required for receiving SSI benefits (Hansen et al., 2014). This may also lead 
providers to medicalize distress due to the consequences of poverty in order to give their patients eligibility for financial assistance (Hansen et al., 2014). The UK implemented similar austerity policies in 2013 with their Universal Credit program which enforced stricter conditions for unemployment benefits (Wickham et al., 2020). Studies have shown an increase in mental distress among unemployed participants enrolled in the program by 6.75 percentage points due to anxieties from the threat of losing essential income due to minor infringements and pressure to apply for a high volume of jobs (Wickham et al., 2020). Although the US did not measure similar outcomes regarding mental health with the changes to welfare policy, studies have shown that these reforms increased rates of extreme poverty and increased the number of disconnected unemployed single mothers who were not receiving any government assistance (Matthews, 2016). Child poverty has also increased after these policies were enacted (Nkansah-Amankra et al., 2013). Based on these results, neoliberal efforts to cut spending on social services increase mental distress and disconnect the most at risk individuals from the help that they need.

\section{Neoliberal Ideologies Contributing to Emotional Distress}

Neoliberal ideologies, as mentioned above, have also contributed to distress. Neoliberalism encourages individualism, which has decreased emphasis on the need for community and social connection for fulfillment. Since individualism is viewed as a desirable moral characteristic, asking for help, especially financially, is frowned upon. With complete faith in the free market to provide for all who wish to work, people who do not achieve financial success are blamed for their misfortunes increasing the stigma of poverty. Attitudes toward people who receive government financial assistance can elicit feelings of shame from those who receive benefits (Hansen et al., 2014). Neoliberalism also encourages consumerism and when people adopt materialistic values they are more likely to have symptoms of anxiety and depression with poorer relationships and lower self-esteem (James, 2008). Neoliberal capitalism has also led to mass incarceration and poverty particularly in minority populations (Nkansah-Amankra et al., 2013). Racism and neoliberal ideologies have justified the creation of a disposable population who are viewed as criminals that are unwilling to work (NkansahAmankra et al., 2013). Although it is unclear what is causing increasing suicide rates in Black adolescents, past injustices make it difficult for minorities to escape their financial situations likely leading to hopelessness and poor mental health (Sounding the alarm on black youth suicide, n.d.).

Margaret Thatcher famously stated that there is "no such thing as society, only individual men and women"
(Nkansah-Amankra et al., 2013). However, strong social ties and community are beneficial for mental health and mental disorders are more common among people with fewer friends and weaker community engagement (Hari, 2019). Involvement in community organizations has fallen 45\% between 1985 and 1994, and for many, the immediate family is all that remains as a primary support structure (Hari, 2019). Marriage rates are also declining among white working class people without a college degree, which has been attributed to poor economic prospects (Anne \& Angus, 2020). Researchers John and Stephanie Cacioppo have argued that loneliness is a risk factor for symptoms and anxiety and depression (Cacioppo et al., 2014). Loneliness has been described as an epidemic due to dramatic increases in perceived loneliness since 1980 (Hari, 2019). Union participation was once a source of community for workers, but decreases in union participation has caused this community to disappear (Anne \& Angus, 2020). Wealth inequality has also been cited as a cause of increased loneliness as levels of trust in others has been found to be lower in countries with greater wealth inequality when compared to countries with lesser wealth inequality (Wilkinson \& Pickett, 2011). This is likely also due to competitive attitudes toward others due to ideologies of neoliberal capitalism and competition for social status (Wilkinson \& Pickett, 2011). Social relationships appear to be better in more egalitarian countries including better social cohesion and trust, involvement in community life, and lower levels of violence (Wilkinson \& Pickett, 2011).

Consumerism is another cause of poor mental health and it is especially important in the United States where income is often equated with a person's value and moral character (Moncrieff, 2001). Psychologist Tim Kasser studied how materialistic values affect happiness and found that people who believe that happiness comes from accumulating things and having a superior status are more likely to have symptoms of anxiety and depression (Hari, 2019). He also found that people driven more by extrinsic motives, meaning that they mostly do things in order to get something in return, are more likely to have shorter and less meaningful relationships than people who are driven by intrinsic motives, meaning that they do things because they enjoy them (Hari, 2019). Materialists were also found to be more competitive and have lower self-esteem (James, 2008). When a person's self worth is determined by material factors, which are out of their control, their self-esteem is vulnerable to fluctuations (James, 2008). Consumerism is closely tied to status competition and when there is a greater emphasis on social status due to income inequality, extrinsic values are more important for increasing social status (Wilkinson \& Pickett, 2011). Putting high values on status and constantly competing and comparing oneself to others is exhausting and does not provide what humans need for fulfillment (James, 2008). 
Suicide attempts by Black adolescents have surgedby $73 \%$ between 1991 and 2017 (Sounding the alarm on black youth suicide, n.d.). This has become an area of concern within the psychiatric community but there are no definitive answers as to what caused this increase. Some cite the lack of access to healthcare, mistrust of the medical system, systemic injustice, and shame as possible factors but more research is needed to better understand this phenomenon (Sounding the alarm on black youth suicide, n.d.). Neoliberal policies have disproportionately impoverished minority populations and therefore, must be considered as a possible factor influencing these suicide rates. The neoliberal policy changes contributing to increased poverty rates and poor health outcomes has affected minority populations disproportionately with Black and Latino poverty being three times higher than poverty rates in White populations (Nkansah-Amankra et al., 2013). Furthermore, neoliberal policies of increased incarceration and harsher sentencing has disproportionately affected minority populations so that minorities are three times more likely to be incarcerated than Whites for the same offense (Nkansah-Amankra et al., 2013). Incarceration has long lasting effects and reduces former offenders' likelihood of employment, results in poorer mental health when compared to non-incarcerated individuals, and has been shown to strain parenting and long term partnerships (Nkansah-Amankra et al., 2013). These disproportionate outcomes in minority populations are not by accident and are part of a long history of racism within capitalism. Political scientist Cedric Robinson described this phenomenon as "racialized capitalism" and that capitalism is structured by "racialism" which is the legitimization of an existing social order by differentiating natural or cultural characteristics of the exploited groups by "races" to justify their exploitation (Issar, 2020). This has taken different forms throughout history in practices such as colonization, slavery, seizure of indigenous land, and housing redlining (Issar, 2020). Today, neoliberalism claims to be "color blind" because the market is fair and distributes wealth based on hard work. Race is not taken into account when it comes to who can achieve success because the free market is able to provide for all who wish to work regardless of their racial background. However, this ignores the long history of deeply rooted social inequities and does not recognize how minorities have been economically disadvantaged in the past through racist policies and practices (i.e. slavery, Jim Crow, redlining) (Issar, 2020). Additionally, social mobility is more difficult due to neoliberal policies that give more advantages and opportunities to the wealthy (Nkansah-Amankra et al., 2013). Instead, minorities are directly blamed for their own poverty often by using racist tropes, including black people being "lazy" and "not wanting to work" or using the trope of the "welfare queen" to justify the evisceration of welfare programs (Pulido, 2016). This justifies the creation of a disposable group of people that is needed in order to continue the accumulation of power and profit for the rich (Pulido, 2016). This disposable group has historically been the poor, segregated, people of color left vulnerable by deindustrialization and reduction of social services (Nkansah-Amankra et al., 2013; Pulido, 2016). This population is disproportionately subject to police violence and incarceration with decreased investment into their communities leading to poor infrastructure, which is all justified by neoliberal ideology and racism.

Although direct causes the of increased suicide attempts in black youth have not been identified, it may be partially due to a sense of hopelessness that Black youth will be unable to lead lives where they do not suffer. Furthermore, minority groups frequently lack access to mental healthcare. Black adolescents are significantly less likely to receive mental health care for depression and in 2018, 58.2\% of Black young adults ages 18-25 with a serious mental illness did not receive treatment (Black and African American Communities and Mental Health, n.d.). A Black male born in the United States today can expect to be incarcerated by age 14 and have a life expectancy that is 5-10 years shorter than his white counterpart (Nkansah-Amankra et al., 2013). This must have some effect on the mental wellbeing of Black adolescents. A recent study showed that police killings of unarmed Black Americans negatively affects the mental health of Black American adults (Nix \& Lozada, 2020). By blaming minorities for their own economic disadvantages and treating minorities as criminals undeserving of support and investment, neoliberalism continuously fails people of color and likely contributes to the mental health crisis we are seeing today.

\section{Neoliberal Influence on Mental Healthcare}

Neoliberal capitalism does not just increase distress and contribute to rising rates of psychiatric disorders, it also dictates how we go about diagnosis and treatment of mental distress. The way that psychiatry is practiced has been guided by profitability in recent years due to the for-profit healthcare system and influence of the pharmaceutical industry (Davies, 2017). Around the same time as the cultural shifts of neoliberalism began, psychiatry moved to a biological approach and the scope of psychiatry expanded which worked to medicalize distress, shift cultural perception about what is "normal" and what is "abnormal", and strengthen the idea that failure to succeed in the dominant society is an individual problem that must be corrected by individual treatment (Cohen, 2017).

The statistics from the first section of this paper detailing rising rates of mental illness and antidepressant prescription can be used to illustrate how societal pressures from neoliberalism have caused distress, yet can also illustrate how the 
practice of psychiatry has changed in the neoliberal era. The publication of the DSM III in 1980 shifted psychiatry from psychodynamic approaches of describing mental illness into a more biological domain that established descriptive categories of subjective states (Davies, 2017). The pharmaceutical industry worked to link the DSM descriptive diagnoses to biological abnormalities and began to promote biological psychiatry by investing in public health campaigns, funding individual psychiatrists supportive of the biological approach, and financing nearly all clinical trials into psychiatric medication (Davies, 2017). Treating psychiatric illness through medication is also more cost effective as a clinician can now see 3-4 people in the space of a $1 \mathrm{~h}$ session and is therefore favored by profit driven health insurance companies (Davies, 2017). Some of these changes were driven by profits but they also worked to legitimize the neoliberal social order (Cohen, 2017; Davies, 2017). The DSM III increased the number of mental disorders from 182 to 265 , which medicalized subjective experiences that had previously fallen outside of the psy-professional domain (Cohen, 2017). The DSM itself went beyond psychiatry as it started being used not only in clinical settings but also in courts, research, insurance re-imbursement, managed care, and for patients to self-diagnose (Cohen, 2017). It has been used in our society at large to categorize people as "normal" or "sick" (Cohen, 2017). This constitutes a larger shift of social order being dictated by civil society rather than by direct authority by the state (Cohen, 2017). Psychiatry is particularly powerful because it dictates what is a "normal" or "abnormal" response to life stressors (Cohen, 2017). These distinctions are inherently biased because they are based on the assumptions of market principles as rationality (Cohen, 2017; Esposito \& Perez, 2014). Definitions of normal and abnormal mental states are defined by cultural factors and those who are upset by the status quo may be labeled as mentally ill even when existing circumstances are unjust. An example of this was the increased rates of schizophrenia in African American males during the civil rights era who were described by psychiatrists at the Ionia State Hospital as delusional and paranoid when they spoke out about racial injustice (Metzl, 2011). Outside of psychiatric institutions, neoliberal health and wellness discourses allow for a more subtle social control that governs people's behavior at a distance and encourages people to self-monitor for symptoms of mental illness that can be diagnosed and corrected to maximize a person's own productivity (Cohen, 2017; Esposito \& Perez, 2014).

As psychiatric discourse expanded, so have the number of symptoms that constitute as mental illness leading to the medicalization of normal responses to the stressors of life under neoliberal capitalism (Cohen, 2017; Moncrieff, 2001). This has allowed for further enforcement of ruling class values and self-regulation (Cohen, 2017).
Furthermore, the diagnosis of a mental illness is often contingent upon negatively affecting a person's performance at work, school or home indicating that being unsuccessful within the neoliberal order is an individual illness needing to be corrected rather than a problem with the social order itself (Cohen, 2017; Esposito \& Perez, 2014). More recently, the idea of psychiatric illness as a strictly biological neurochemical imbalance has shifted to a biopsychosocial model that takes things such as social circumstance and life experience into a formulation for an individual's experience. However, prescribing medication and individual psychotherapeutic intervention to help our patients become more successful in the neoliberal capitalist society perpetuates the idea that they are ill and defective for not assimilating to it (Cohen, 2017; Esposito \& Perez, 2014). This not only re-enforces ideals of individualism but absolves people in power from the responsibilities for the social conditions and injustices that contribute to distress (Thomas et al., 2020). Furthermore, the primary solution to people who may be depressed or anxious is medication, a product that is advertised as a way for people to be more competitive and successful, thereby perpetuating consumerism (Esposito \& Perez, 2014). Unfortunately, as providers, individualized treatment with medication and psychotherapy are often the only options we're able to offer because modifying a person's social environment and changing policy is outside of our capabilities in the clinic (Esposito \& Perez, 2014).

The cost of health insurance and treatment is also a barrier for access to mental healthcare, often causing patients to wait to see a provider until an emergency occurs. Nearly 60 million adults and children living with mental illness go without treatment in the United States due to high rates of denial of care by insurance providers, high out-of-pocket costs, and problems finding in-network providers (TheDoctor-is-Out, n.d.). The privatization of healthcare in the United States has caused costs to rise much higher than healthcare costs in other countries, yet health outcomes and life expectancy are worse (Case \& Deaton, 2020). Although citizens, politicians, and healthcare providers have advocated for a publicly-funded healthcare system, advocates are overpowered by healthcare lobbyists (Case \& Deaton, 2020). In 2018 the healthcare industry spent more than $\$ 567$ million dollars on lobbying, with more than half of the contributions coming from pharmaceutical companies (Case \& Deaton, 2020). Health care is considered a commodity rather than a social right and as a result there is disproportionate access to healthcare so that the unemployed or underemployed do not have access to healthcare and therefore have worse outcomes (Nkansah-Amankra et al., 2013). Poor health is also a major contributor to poverty since healthcare can be costly (Nkansah-Amankra et al., 2013). The privatization 
of healthcare is a drastic example of how the free market is unable to provide public services.

\section{Advocating for Change}

With heightened status insecurity, the shame of requiring assistance, a bleak economic future with meaningless work, no community to turn to, and an inability to access mental healthcare, it is not surprising that more people are turning to suicide and substance abuse. Although it has been clearly demonstrated through the above-mentioned studies that the policies associated with neoliberal capitalism have been hurting the working class, the United States continues to hold on to neoliberalism as if it is the only way forward. This is by no means an exhaustive description of the number of ways that neoliberal capitalism contributes to mental and physical suffering. Expanding neoliberalism globally through coercive and violent tactics has caused suffering in other countries, the lack of environmental regulations for corporations has worsened global warming, and there countless other consequences that have not been mentioned. The mental distress that has been caused by these policies gives us a unique opportunity as mental health providers to advocate for change. We must address these disturbing trends of increased mental illness, suicide, overdose deaths, and alcoholism in a more comprehensive way by becoming more politically engaged, making changes to the ways that we practice, and addressing issues with the current social order with patients.

As a field we should invest more into educating providers about structural competency, which teaches about how social, economic, and political forces cause health inequalities (Metzl \& Hansen, 2018). This can not only help providers with their own biases perpetuated by neoliberal capitalist ideologies and examine institutional attitudes that can interfere with treatment, but can also help providers learn how to better advocate for their patients through community based advocacy projects (Metzl \& Hansen, 2018). We should also continue to look at social and environmental causes of mental illness through research and try to approach mental illness through multi-disciplinary care rather than through pharmaceuticals if possible. We must involve social workers, therapists, and community organizations in care to help with treatment. We should also try to focus less on work and productivity as benchmarks for recovery and focus on other goals that patients may have instead.

Individually, providers could also look at the specific stressors caused by neoliberal capitalist policies and try to mitigate them with psychosocial interventions or referrals to local organizations and programs able to address economic stressors. One way to do this is by strengthening community engagement. In the 1960s and 1970s, the social psychiatry movement saw similar issues with environmental causes of mental illness (Smith, 2016). Proponents of social psychiatry believed that the best way to address this issue was through the creation of community mental health centers to frame mental health as a community issue and for psychiatrists and other providers to take a more civically active role (Smith, 2016). However, there were several issues with community health centers, which included funding cuts by the Reagan administration, lack of coordination between inpatient and outpatient care, and cultural and racial tensions between the mental health professionals and the patients they served (Smith, 2016). A resurgence of the movement for community mental health centers could help address issues of social isolation, provide patients with resources for education and social mobility, and provide opportunities for civic engagement. Past failures to implement community mental health centers should be closely studied to avoid repeating earlier mistakes (Smith, 2016). Another possible intervention is Integrative Community Treatment (ICT), which is a psychosocial intervention originating in Brazil used to address social isolation during the COVID-19 pandemic (Barreto et al., 2020). ICT facilitates groups among community members that involve strengthening social bonds and building community support networks (Barreto et al., 2020). This strategy could be used in the United States where deaths from suicide, opioid overdose and alcoholic liver cirrhosis are high. Providers could also work with patients individually on ways to cope with the stress of loneliness, materialism, and status competition.

However, these interventions would not address the policy changes needed for a more comprehensive solution. Although supportive individual treatment through medication and psychotherapy are helpful to many, the cultural and economic issues due to neoliberal capitalism also need to be addressed due to the scale of the problem we are facing and the limited number of mental health providers available. One possible avenue is for mental health providers to support national policies that facilitate more equal income distribution and universal health insurance through our professional organizations. It is also important that mental health providers support policies that address the power dynamics between employers and employees, such as advocating for limitations on lobbying, unionization, cooperative business models, and regulation preventing industry monopolies (Case \& Deaton, 2020). Providers can also get involved with advocacy at the state level by testifying at state legislative hearings to support efforts such as state proposals to increase minimum wage and increase state spending on public services to decrease mental health burdens. These socio-political causes of mental distress have affected so many and can 
only be achieved by widespread governmental interventions that help people instead of profit margins.

\section{Declarations}

Conflict of interest This author has no relevant or non-relevant financial interests to disclose and no conflicts of interest that are relevant to the content of this article. The author certifies that they have no affiliations with or involvement in any organization or entity with any financial interest or non-financial interest in the subject matter or material discussed in this manuscript. The author has no financial or proprietary interests in any material discussed in this article.

Research Involving Human and Animal Rights There were no human or animal research participants in the making of this article.

\section{References}

Allen, J., Reuben, B., Ruth, B., \& Michael, M. (2014). Social determinants of mental health. International Review of Psychiatry, 26(4), 392-407. https://doi.org/10.3109/09540261.2014.928270

Black and African American Communities and Mental Health (n.d.). Retrieved from https://www.mhanational.org/issues/black-andafrican-american-communities-and-mental-health.

Cacioppo, S., John, C., \& John, C. (2014). Toward a neurology of loneliness. Psychological Bulletin, 140(6), 1464-1504. https://doi. org/10.1037/a0037618

Case, A., \& Deaton, A. (2020). Deaths of despair and the future of capitalism. Princeton University Press.

Cohen, B. M. (2017). Psychiatric hegemony: A marxist theory of mental illness. Palgrave Macmillan.

De PaulaBarreto, A., Di Nicola, V., Filha, M. O. F., \& da Silva, M. Z. (2020). Integrative community therapy in the time of the new coronavirus pandemic in Brazil and Latin America. World Social Psychiatry, 2(2), 1-3. https://doi.org/10.4103/WSP.WSP_46_20

Davies, J. (2017). The sedated society: The causes and harms of our psychiatric drug epidemic. Palgrave Macmillan.

Esposito, L., \& Perez, F. M. (2014). Neoliberalism and the Commodification of Mental Health. Humanity \& Society, 38(4), 414-442. https://doi.org/10.1177/0160597614544958

Hansen, H., Bourgois, P., \& Drucker, E. (2014). Pathologizing poverty: New forms of diagnosis, disability, and structural stigma under welfare reform. Social Science \& Medicine, 103, 76-83. https:// doi.org/10.1016/j.socscimed.2013.06.033

Hari, J. (2019). Lost connections: Why you're depressed and how to find hope. Bloomsbury Publishing.

Harvey, D. (2005). A brief history of neoliberalism. Oxford University Press. https://doi.org/10.1093/oso/9780199283262.001.0001

Issar, S. (2020). Listening to Black lives matter: Racial capitalism and the critique of neoliberalism. Contemporary Political Theory, 20(1), 48-71. https://doi.org/10.1057/s41296-020-00399-0

James, O. (2008). The selfish capitalist: Origins of affluenza. Vermilion.

Matthews, D. (2016). "If the goal was to get rid of poverty, we failed": The legacy of the 1996 welfare reform. Retrieved June 20, 2016, from https://www.vox.com/2016/6/20/11789988/clintons-welfa re-reform

Metzl, J. (2011). The protest psychosis: How schizophrenia became a black disease. Beacon.

Metzl, J. M., \& Hansen, H. (2018). Structural competency and psychiatry. JAMA Psychiatry, 75(2), 115. https://doi.org/10.1001/jamap sychiatry.2017.3891
Mishel, L., and Kandra, J. (2020). Wages for the top 1\% skyrocketed $160 \%$ since 1979 while the share of wages for the bottom $90 \%$ shrunk: Time to remake wage pattern with economic policies that generate robust wage-growth for vast majority. Retrieved December 1, 2020, from https://www.epi.org/blog/wages-for-thetop-1-skyrocketed-160-since-1979-while-the-share-of-wages-forthe-bottom-90-shrunk-time-to-remake-wage-pattern-with-econo mic-policies-that-generate-robust-wage-growth-for-vast-majority/

Moncrieff, J. (2001). Neoliberalism and biopsychiatry: A marriage of convenience. Liberatory Psychiatry. https://doi.org/10.1017/ cbo9780511543678.013

Nix, J., \& Lozada, M. J. (2020). Police killings of unarmed Black Americans: A reassessment of community mental health spillover effects. Police Practice and Research. https://doi.org/10.31235/ osf.io/ajz2q

Nkansah-Amankra, S., Agbanu, S. K., \& Miller, R. J. (2013). Disparities in health, poverty, incarceration, and social justice among racial groups in the United States: A critical review of evidence of close links with neoliberalism. International Journal of Health Services, 43(2), 217-240. https://doi.org/10.2190/hs.43.2.c

Products - Data Briefs - Number 283 - August 2017. Centers for disease control and prevention. Retrieved August 15, 2017, from https:// www.cdc.gov/nchs/products/databriefs/db283.html

Pulido, L. (2016). Flint, environmental racism, and racial capitalism. Capitalism Nature Socialism, 27(3), 1-16. https://doi.org/10. 1080/10455752.2016.1213013

Sounding the alarm on black youth suicide. (n.d.). Retrieved from https://www.apa.org/news/apa/2020/black-youth-suicide

Shade, Colette. (2021). The problem with mental health awareness. Retrieved January 26, 2021, from https://www.thenation.com/artic le/society/mental-health-awareness/

Shaikh, A. (2014). The economic mythology of neoliberalism. Neoliberalism. https://doi.org/10.2307/j.ett18fs4hp.8.

Smith, M. (2016). A fine balance: Individualism, society and the prevention of mental illness in the United States, 1945-1968. Palgrave Communications. https://doi.org/10.1057/palcomms.2016. 24

Stansfeld, S., Rebecca, F., Martin, S., \& Michael, M. (1999). Work characteristics predict psychiatric disorder: Prospective results from the Whitehall II Study. Occupational and Environmental Medicine, 56(5), 302-307. https://doi.org/10.1136/oem.56.5.30

The Doctor is Out. (n.d.). Retrieved from https://www.nami.org/ Support-Education/Publications-Reports/Public-Policy-Reports/ The-Doctor-is-Out

The State of Mental Health in America. (2021). Retrieved from, https:// www.mhanational.org/issues/state-mental-health-america

Thomas, F., Wyatt, K., \& Hansford, L. (2020). The violence of narrative: Embodying responsibility for poverty-related stress. Sociology of Health \& Illness, 42(5), 1123-1138. https://doi.org/10. 1111/1467-9566.13084

Wickham, S., Bentley, L., Rose, T., Whitehead, M., Taylor-Robinson, D., \& Barr, B. (2020). Effects on mental health of a UK welfare reform, universal credit: A longitudinal controlled study. The Lancet Public Health, 5(3), e157-e164. https://doi.org/10.1016/ s2468-2667(20)30026-8

Wilkinson, R., \& Pickett, K. (2011). The spirit level why greater equality makes societies stronger. Bloomsbury Press.

Publisher's Note Springer Nature remains neutral with regard to jurisdictional claims in published maps and institutional affiliations. 